\title{
Solidaridad en la gubernamentalidad liberal avanzada: un análisis en piezas publicitarias ${ }^{1}$
}

\author{
M. Alejandra Energici S. \\ Universidad Alberto Hurtado, Santiago, Chile. \\ Email: menergic@uahurtado.cl \\ José Antonio Román B. \\ Universidad Alberto Hurtado, Santiago, Chile. \\ Email: jroman@uahurtado.cl \\ Claudio Ramos Z. \\ Universidad Alberto Hurtado, Santiago, Chile. \\ Email: cramos@uc.cl

\section{Sebastián Ibarra G.} \\ Universidad Alberto Hurtado, Santiago, Chile. \\ Email: sibarra@uahurtado.cl
}

\begin{abstract}
Resumen: El artículo presenta una reflexión sobre la manera en que en los últimos veinte años la promoción de un determinado tipo de solidaridad en Chile ha contribuido a la conformación de una gubernamentalidad liberal avanzada, necesaria para la instalación de un programa neoliberal. La reflexión se enmarca en los aportes teóricos de Michel Foucault y tiene por objeto empírico piezas de publicidad de promoción de la solidaridad emitidas en Chile entre los años 2009 y 2010, que han sido analizadas en el contexto del proyecto Fondecyt 1090534. Se presentan tres tipos de resultados: (a) se describen los sectores sociales que se construyen como agentes de la solidaridad, (b) se reflexiona sobre las prácticas solidarias más promovidas y (c) se indaga en la forma en que se interpela a los sujetos a ser solidarios.
\end{abstract}

Palabras clave: solidaridad, gubernamentalidad liberal, publicidad.

\section{Solidarity in an advanced liberal governmentality: an analysis of advertising ads}

\begin{abstract}
The article presents an analysis on the way in which during the last twenty years the promotion of a certain kind of solidarity in Chile has contributed to the formation of an advanced liberal governmentality, necessary for the installation of a neoliberal agenda. The reflection follows the theoretical contributions of Michel Foucault and focuses on the empirical analysis of ads that promote solidarity, issued in Chile between 2009 and 2010, in the context of the project FONDECYT 1090534. We present three types of results: (a) description of the social sectors that are
\end{abstract}


constructed as agents of solidarity, (b) analysis on the most promoted solidarity practices and (c) investigation on the way it adresses the people in order to raise their solidarity.

Key words: solidarity, liberal governmentality, advertising

\section{Solidariedade em uma governamentalidade liberal avançada: uma análise de anúncios publicitários}

Resumo: O artigo apresenta uma reflexão sobre como a maneira de incentivar um certo tipo de solidariedade no Chile tem contribuído para a formação de uma governamentalidade liberal avançada, necessária para a instalação de uma agenda neoliberal. A reflexão recai sobre as contribuições teóricas de Michel Foucault e analisa anúncios para promover a solidariedade emitida no Chile entre 2009 e 2010, no contexto do projeto Fondecyt 1090534. Nós apresentamos três tipos de resultados: (a) descreve os setores sociais que são construídas como agentes de solidariedade, (b) reflete sobre as práticas de solidariedade mais promovidos e (c) investiga a forma como ele desafia o sujeito a ser solidário.

Palavras-chave: a solidariedade, governamentalidade liberal, a publicidade

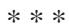

\section{Antecedentes: mutación de la solidaridad en Chile}

En la historia republicana occidental la palabra “solidaridad” se ha utilizado para defender distintos intereses sociales y políticos, como invocar la justicia social, la igualdad de derechos y la caridad cristiana, por nombrar algunos. En su nombre se han abordado asuntos sociales, políticos y económicos cruciales, como son el rol del Estado, la sociedad civil y el sector privado en la protección de los más desfavorecidos. Y se la ha usado en cuestiones tan diversas como son la libertad de prensa y expresión, la defensa de la vida en el caso de la violación de los Derechos Humanos y la invitación a comprar un producto “solidario” (Dockendorff, 1993; Román \& Energici, 2006; Román, Tomicic, \& Avendaño, 2007; Román \& Energici, 2010; Dockendorff, Román, \& Energici, 2010).

Particularmente, realizando un breve recorrido histórico, podemos apreciar los diversos sentidos que ha vehiculizado la noción de solidaridad en los últimos 40 años en Chile.

Durante la época de la Unidad Popular (1971-1973), la solidaridad se vinculaba al ejercicio de la justicia social y la caridad cristiana (Dockendorff, Román y Energici, 2010). El Estado era una institución protagónica en la gestión y coordinación de la solidaridad. Las pocas ONG de la época (aproximadamente 40) contaban con importantes beneficios tributarios en un contexto de relaciones fluidas con el aparato público (Cancino, 1996). La participación solidaria se realizaba concurriendo en las instancias e instituciones públicas, por ejemplo, a través del pago de impuestos. Muchas de las prácticas solidarias de este período implicaban 
una reflexión crítica sobre la falta de equidad en Chile y se vinculaban explícitamente con asuntos políticos y económicos: cuestiones de derechos, equidad, propiedad pública y trabajo, por nombrar algunos.

Con el Gobierno Militar el país sufre una serie de cambios políticos, sociales y económicos que determinan un nuevo contexto para la construcción de la solidaridad. En 1975, en un contexto de violación sistemática de los Derechos Humanos por parte del Estado, se comenzó a implementar un proyecto neoliberal (Garretón, 1983). Dentro de este período podemos identificar al menos dos grupos de sentidos que fueron vehiculizados con el término solidaridad. Un primer conjunto de significados fueron asociados a justicia e igualdad de derechos (Dockendorff, Román y Energici, 2010). Ejemplo de estas son la labor de instituciones como el Comité Pro Paz y la Vicaría de la Solidaridad que se abocaron a la defensa y promoción de los derechos humanos. Dentro de este mismo grupo podemos mencionar la solidaridad popular, donde las ollas comunes fueron una de las formas de organización social más recurrentes de la época (Hardy, 1986). El segundo, se asocia con la instalación del proyecto neoliberal, e incluye una solidaridad entendida como caridad desde la iniciativa privada, favorecida por el Estado. Se sentaron las bases jurídicas e institucionales para el traspaso de la solidaridad desde el Estado al tercer sector y el sector privado. Para esto se crearon franquicias tributarias que permitirían la creación de un tercer sector financiado con un importante aporte privado. Ejemplo de esta solidaridad fue la creación de la Teletón en 1978, al amparo de esta nueva ley. (Asociación de la Distrofia Muscula, s/f). El evento contó desde el inicio con la aparición de celebridades y una activa participación empresarial. Hasta la fecha, es una de las acciones emblemáticas en cuanto a la participación del sector privado con fines de lucro en la solidaridad.

Una vez finalizada la dictadura militar, la solidaridad continuó su traspaso a la sociedad civil, dejando de ser entendida como una responsabilidad fundamental del Estado para considerarse progresivamente como un asunto de toda la sociedad (Dockendorff, Román y Energici, 2010), delegado en el tercer sector. Luego del triunfo electoral de Patricio Aylwin, hubo una oleada de nuevas ONG (Cancino, 1996). No obstante, el tercer sector perdió el financiamiento que obtenía de la cooperación internacional y se ha dedicado, desde entonces, a la ejecución de acciones y programas de política social (de la Maza, 2003). En este sentido, es un tercer sector, que si bien es grande, no cuenta con una gran autonomía y que se constituye como efecto de la flexibilización del sector público con un importante aporte privado (Román, 2009).

La instalación del programa neoliberal ha conllevado al surgimiento y protagonismo de una versión que se ha nominado como solidaridad de mercado que se asocia a actividades comerciales y de consumo (Román y Energici, 2006, 2010, Dockendorff, Román y Energici, 2010). Así, la solidaridad en el contexto de una compra se ha vuelto la práctica más frecuente: en la Encuesta de Solidaridad 2007 el 62\% de los encuestados declaró donar el vuelto de una compra en un supermercado o farmacia una vez por 
semana, constituyéndose como la práctica solidaria más recurrente (Román \& Ibarra, 2008). Esto coincide con otros estudios, González y Cortes (2009) obtienen resultados similares en el Índice de Solidaridad: el 85\% de los encuestados declara realizar donación de dinero, donde el 75,1\% dona parte del vuelto siempre o casi siempre. Esto contrasta con la baja frecuencia con que se declara realizar acciones de voluntariado: en la Encuesta de Solidaridad 2007 más del 70\% de los encuestados afirmó realizar estas actividades nunca o una vez al año (Román \& Ibarra, 2008). Otros estudios presentan valores más bajos aún: en el estudio realizado por Trascender Collect (2008) en el 2007 sólo el 9\% de los encuestados declaró haber realizado alguna actividad de voluntariado durante los últimos doces meses, porcentaje que cae a un 8\% para el 2008.

Por otro lado, la participación de la solidaridad en el mercado puede apreciarse en el incremento de inversión publicitaria por parte de instituciones de beneficencia. De acuerdo al informe sobre Inversión Publicitaria 2008 realizado por ACHAP y Megatime, del 2007 al 2008 la inversión realizada por la categoría "Beneficencia” aumentó en un 26\%, posicionándose como la tercera categoría que más aumentó su inversión (después de “Hipermercados” y “Limpieza”). Asimismo, en el ranking de inversión por categoría del 2008, “Beneficencia” quedó posicionado en el décimo lugar superando categorías como "Limpieza”, “Farmacias”, “Instituciones Financieras” y "Gaseosas” (ACHAP y Megatime, 2009).

Por último, un estudio que analizó publicidad de campañas de ayuda o promoción de la solidaridad apoya la idea del creciente protagonismo que esta ha tenido en el mercado. La solidaridad ha pasado a resolverse como un negocio, vendiéndose como cualquier otra mercancía en el mercado y ofertándose como una acción cómoda y fácil en una modalidad de solidaridad “a la carta” (Román y Energici, 2006). Se trata de una solidaridad de mercado, pues éste se levanta como la instancia para resolver la solidaridad a través de un segmento especializado: una oferta diversa de formas de consumo-ayuda gestionada por la empresa privada en alianza estratégica con las instituciones de beneficencia, destinada a transformar en ayuda el aporte de un consumidor altruista (Román, Tomicic, \& Avendaño, 2007, Román y Energici, 2010).

\section{La solidaridad en el contexto de una gubernamentalidad liberal}

El estudio que se presenta a continuación explora la manera en que la promoción de la solidaridad contemporánea contribuye a la conformación de una ethopolítica afín a una gubernamentalidad liberal avanzada. Por ethopolítica, se entienden “...las políticas de la vida misma y sobre cómo debe ser vivida...” (Rose, 2001), es decir, aquellos imperativos morales de la vida cotidiana a través de los cuáles individuos se autogobiernan. 
De este modo, lo que interesa es cómo una determinada promoción de cierto tipo de solidaridad contribuye a la instalación de una moral, en que el autogobierno de los individuos es concurrente con una gubernamentalidad liberal avanzada.

\section{Las gubernamentalidad liberales}

Foucault (2007) definió una gubernamentalidad como un arte de gobierno específico. La particularidad de cualquier gubernamentalidad liberal, es el cuestionamiento constante sobre cómo no gobernar demasiado. Es una actividad que permanentemente pregunta, calcula y proyecta hasta dónde debe gobernar, intentando siempre optar por la menor conducción posible.

Las distintas formas de gubernamentalidades liberales, como el gobierno mínimo o frugal (Foucault, 2007), el liberalismo social o la gubernamentalidad liberal avanzada (Dean, 2010; Rose, 2007) podemos caracterizarlas atendiendo a dos dimensiones, una biopolítica y una subjetivante. Para cada una de estas dimensiones, la solidaridad se vuelve un objeto de interés.

\section{Dimensión subjetivante}

Cada forma de gobierno requiere de la producción de un tipo de sujeto específico: la transformación de los seres humanos en sujetos, en este caso libres, es una estrategia de dominación que implica un sometimiento a otros (sujeto de) y al sí mismo (sujeto a) en tanto que implica atarse a la propia identidad de una manera impuesta (Foucault, 1988). El gobierno opera sobre los deseos, aspiraciones o intereses, no coartándolos o coaccionándolos, sino produciendo los sujetos que tengan los deseos, aspiraciones o intereses correctos (Foucault, 2006) o afines a la forma de gobierno.

En este sentido, las gubernamentalidad liberales funcionan sobre los intereses. Estos son el medio a través del cual el gobierno tiene influjo sobre los individuos, los actos, las palabras, las riquezas, los recursos, las propiedades, los derechos, etc. Gobernar es manipular intereses individuales y colectivos. El gobierno ya no debe intervenir directamente sobre las cosas y las personas, sino que es más bien una "república fenoménica de los intereses” (Foucault, 2007, pág. 66).

Parte importante de las prácticas subjetivantes (es decir, aquellas que tienen por efecto un sujeto), son las prácticas morales. El estudio de las prácticas solidarias permite indagar en las formas en que se construye una moral afín a un tipo de gubernamentalidad liberal, ya que la solidaridad, cualquiera sea su versión (desde las nociones más altruistas hasta la solidaridad como fundamento del vínculo social) es siempre parte de una moral. Cada forma de solidaridad contiene una norma sobre las relaciones sociales, y en tal sentido, las distintas versiones de la solidaridad van aparejadas 
con cierto ethos sobre los vínculos sociales. Toda forma de solidaridad debe responder preguntas tales como: ¿en qué consiste ser solidario?, ¿por qué se debe ser solidario?, ¿quién debe ser solidario?, ¿con quién se debe ser solidario? La solidaridad instala una moral (o se instala con una moral) en torno a la cual los seres humanos se constituyen como sujetos. Es así como, las prácticas solidarias son subjetivantes, en tanto que vuelven a un individuo sujeto de otros y sujeto de sí mismo a través una moral o ethos solidario.

\section{Dimensión biopolítica}

Las distintas formas de gubernamentalidades liberales pueden caracterizarse por el modo en que tienden a resolver la dramática libertad/ seguridad. Las gubernamentalidades liberales, son tales porque son consumidoras de libertad. Una gubernamentalidad liberal puede operar sólo en la medida en que se garanticen una serie de libertades (libertad de mercado, libertad de vendedor y comprador, libre ejercicio del derecho de propiedad, libertad de expresión, etc.). Consumen las libertades que deben ser capaces de producir. El liberalismo no es, entonces, un imperativo de la libertad, sino la administración y organización de las condiciones en las que se puede ser libre. La libertad es algo que se fabrica a cada instante enfrentando el conjunto de coacciones y problemas de costos que plantea esa fabricación (Foucault, 2007).

El principio de cálculo de costo de producción de la libertad es la seguridad. "Es decir que el liberalismo, el arte liberal de gobernar, se verá forzado a determinar con exactitud en qué medida y hasta qué punto el interés individual, los diferentes intereses, individuales en cuanto divergen unos de otros y eventualmente se oponen, no constituyen un peligro para el interés de todos. Problema de seguridad: proteger el interés colectivo contra los intereses individuales. A la inversa, lo mismo: habrá que proteger los intereses individuales contra todo lo que pueda aparecer, en relación con ellos, como una intrusión procedente del interés colectivo” (Foucault, 2007, pág. 86). Así, la economía de poder propia del liberalismo es el juego entre libertad y seguridad (Foucault, 2007).

La solidaridad, por su parte, se engarza en la médula libertad/ seguridad: el objeto de la solidaridad es, en último término, el establecimiento de las condiciones de seguridad mínimas para toda la población (por ejemplo, en una gubernamentalidad liberal social) o para aquellos grupos que no pueden resolver su supervivencia (por ejemplo, en una gubernamentalidad liberal avanzada). Dicho de otro modo, el problema de la solidaridad es la seguridad básica ${ }^{2}$. Este problema debe ser resuelto respetando las libertades garantizadas, tanto de quienes deben ser ayudados, como de quienes deben ayudar. La solidaridad cumple una función sobre la seguridad de la población, al mismo tiempo que respeta y aporta a la fabricación de las libertades que permitan la gestión de esa seguridad. 


\section{Solidaridad y publicidad en una gubernamentalidad liberal}

A continuación abordaremos la cuestión de la contribución de la promoción de determinado tipo de solidaridad a la construcción de un ethos solidario afín a una gubernamentalidad liberal avanzada, en cuanto práctica subjetivante.

Considerando la alta participación de la solidaridad en el mercado y el incremento de la inversión publicitaria en beneficencia, la publicidad se vuelve un campo de estudio privilegiado para indagar en la solidaridad de mercado y su vinculación a las actividades de consumo, y el análisis de las piezas publicitarias se constituye como una vía metodológicamente productiva para esa reflexión.

Pero para eso, es importante, tener teóricamente a la vista las funciones básicas de la publicidad en que esta solidaridad se promociona. Siguiendo a Foucault (2007), en una sociedad donde el mercado se constituye como el espacio donde se resuelven los asuntos fundamentales de una sociedad, podemos postular que la publicidad cumple al menos tres funciones tecnológicas subjetivantes básicas.

\section{La publicidad como tecnología de simulacro}

En primer término, cuando el consumo se vuelve la forma de participación social (Cortina, 2002), este no tiene como objetivo la satisfacción de necesidades, sino que es más bien la manipulación de signos. Es decir, los objetos que se consumen no valen por su valor de uso, sino por aquello que significan, consumir es una forma de interactuar e intercambiar signficados sociales (Baudrillard, 2009). El consumo, así, se vuelve una forma de vínculo social.

En este contexto, las necesidades no son un dato previo al consumo, sino más bien un producto de este: el consumo produce necesidades. Y esto se realiza principalmente a través de la publicidad, es en este medio donde el objeto se convierte en signo (Baudrillard, 2009). Dicho de otro modo, en la publicidad se construye un mundo imaginario, donde comprar el producto anunciado es un vale que da derecho a penetrar (imaginariamente) en ese mundo (Ibáñez, 2002). En la publicidad el objeto se vuelve un simulacro de sí mismo, donde poco interesa las propiedades del objeto, más bien, el valor de un objeto es aquello que significa, el mundo del cual es referente.

En este sentido, la publicidad es una tecnología de simulacro, sin la cual el consumo como manipulación de signos y forma de vínculo social no sería posible.

En la publicidad sobre solidaridad interesan los mundos en que se participa al realizar una práctica de ayuda: ¿qué sentidos se le atribuyen a 
la práctica solidaria? ¿cómo es significada? Una misma práctica de ayuda, por ejemplo, donar parte del vuelto de una compra, puede ser significada de diversas maneras: como una acción cristiana, como una ayuda fácil o como un aporte a construir un país más justo.

\section{La publicidad como tecnología moral}

En segundo lugar, la publicidad instala un marco moral: indica quiénes deben consumir qué (realiza una conducción específica de los intereses hacia el consumo). Como efecto, la marca de un producto marca al consumidor (no al producto), lo que permite que la publicidad instale una clasificación de consumidores generando clases o grupos con relaciones de equivalencia y de orden entre sí (Ibáñez, 2002).

De esta manera, los consumidores se constituyen como distintos tipos de sujetos según los productos que adquieran. Si lo tradujésemos en una frase, esta sería: "Sea un buen " $x$ " (padre, madre, hombre, mujer, joven, etc.), consuma "y" producto (teléfono celular, marca de ropa, cigarrillos, seguro de salud, etc.) y forme parte de "z" grupo de estilo de vida (los que están "siempre comunicados", los que ocupan una marca de ropa exclusiva, los que están asegurados ante cualquier eventualidad, etc.)”.

La publicidad cumple una función normativa en tanto que indica quién debe consumir qué. Ahora bien, la moral, o mejor dicho las morales, que instala la publicidad cuentan con una particularidad: son morales que no exigen un compromiso sostenido en el tiempo ${ }^{3}$, son morales desechables, remplazables e incluso superponibles. A través del consumo de un producto un sujeto puede hacerse parte de varios estilos de vida. Así, por ejemplo, en algunas piezas publicitarias se invita al sujeto a donar parte del vuelto de su compra (se le interpela en tanto consumidor) pero apelando a valores cristianos con frases tales como "Su vuelto alimenta nuestra esperanza" (Román \& Energici, 2010). De este modo, en la acción de donar el vuelto se construye como un consumidor-cristiano, es decir, se constituye en torno a dos morales (una del consumo y otra cristiana) que son aparentemente opuestas. Que la publicidad permita la operación de estas morales (desechables, remplazables y superponibles) es fundamental para la lógica de una sociedad de consumo, pues los compradores deben adquirir muchos y variados productos, desechándolos rápidamente, para volver a consumir (Bauman, 2007).

\section{La publicidad como tecnología de consumo}

Hasta acá hemos establecido que la publicidad es una tecnología de consumo en tanto que, a través de la creación de mundos imaginarios y la instalación de morales, permite que este se instale como forma de vínculo y participación social.

Sobre este punto, cabe destacar el consumo como mecanismo de poder: las necesidades son indispensables para el buen funcionamiento del 
consumo como un sistema de manipulación de signos. Baudrillard (2009) afirma que existen necesidades porque el sistema del consumo las requiere. Así, las necesidades son un modo de explotación igual que el trabajo: estamos obligados a consumir. En otras palabras, que el consumo se levante desde el imperativo de una necesidad, es aquello que lo instala como un mecanismo de dominación.

En este sentido, es fundamental que una sociedad donde el consumo ocupa un rol protagónico, las necesidades nunca puedan ser totalmente satisfechas y siempre dejen abierto un espacio para el deseo (Baudrillard, 2009).

Para el caso de las piezas publicitarias sobre solidaridad interesa cómo se insertan dentro de un mercado de la solidaridad que asegura el “consumo” continuo de prácticas solidarias: por ejemplo, que prometan membresías y referentes que se presenten como atractivos que se renueven permanentemente, y que las prácticas ofertadas sean moralmente gratificantes, accesibles y fáciles de realizar.

\section{Presentación de la Investigación}

El estudio que se presenta a continuación analiza la manera en que la promoción de la solidaridad contemporánea contribuye a la conformación de una moral afín a la gubernamentalidad liberal avanzada.

Para tomaremos como corpus 533 piezas publicitarias sobre solidaridad que fueron recolectadas en los siguientes medios ${ }^{4}$ : prensa escrita, lugares públicos (se fotografiaron publicidades en paraderos de micros, las estaciones de Metro y dentro de tiendas comerciales), televisión, Internet, radio y panfletos, trípticos o calcomanías que se repartieran a un público masivo (por ejemplo, el distintivo que se entrega contra la donación en una colecta).

Como primer paso, estas piezas fueron caracterizadas y posteriormente clasificadas según una serie de variables como: medio de emisión, organización emisora, tipo de práctica de solidaridad a que convoca, entre otras. Luego, se procedió a un tipo de análisis semiótico más complejo, utilizando algunas de las categorías de análisis propuestas por van Leeuwen (2005) y Kress (Kress \& van Leeuwen, 1996, 2001), como ruta de lectura, modalidad y recursos lingüístico- discursivos utilizados. análisis:

A continuación se presentarán los siguientes resultados de este

- En primer lugar, se reflexiona sobre los sectores que emiten las piezas publicitarias. Para el análisis se distinguió entre tercer sector, privado con fines de lucro, sector público y alianzas estratégicas entre sectores. En este punto interesa determinar desde qué sopor- 
tes institucionales se emite y se apropia el sentido de la solidaridad. - En segundo lugar, se revisan las prácticas solidarias. A cada pieza se le asignó una variedad de solidaridad, esta se definió en razón de la práctica social a la cual se invita (por ejemplo, donar el vuelto de una compra) o se promueve (por ejemplo, en el caso de RSE la empresa promueve las acciones solidarias que realiza). De esta forma, buscamos caracterizar las prácticas solidarias que más se promueven en la publicidad.

- Por último, se reflexiona sobre el modo en que estas piezas construyen una apelación para promover o solicitar una conducta de ayuda Para esto se consideraron tres tipos de interpelaciones: emocional, racional y moral que serán revisadas más adelante.

\section{Resultados}

\section{La emisión de la publicidad sobre solidaridad}

A partir de un análisis de frecuencias podemos apreciar que más de la mitad de las piezas recolectadas fueron emitidas por instituciones del tercer sector, y que este sector consigue participar en la emisión de 77\% de estas piezas, tal como se puede observar en la Tabla 1.

Tabla 1: Sector de procedencia de las piezas publicitarias (en \%)

\begin{tabular}{|l|l|}
\hline \multicolumn{1}{|c|}{ Sector de procedencia } & $\mathbf{\%}$ \\
\hline Tercer Sector & 50,1 \\
\hline $\begin{array}{l}\text { Alianza Estratégica entre Tercer Sector y } \\
\text { Privados con fines de lucro }\end{array}$ & 26,8 \\
\hline Sector Público & 12,0 \\
\hline Sector privado con fines de lucro & 5,3 \\
\hline $\begin{array}{l}\text { Alianza Estratégica entre Tercer Sector y } \\
\text { sector público }\end{array}$ & 3,2 \\
\hline $\begin{array}{l}\text { Alianza Estratégica entre sector público y } \\
\text { privado con fines de lucro }\end{array}$ & 1,9 \\
\hline $\begin{array}{l}\text { Alianza Estratégica tercer sector, sector } \\
\text { público y sector privado con fines de } \\
\text { lucro }\end{array}$ & 0,8 \\
\hline Total & $\begin{array}{l}100,0 \\
(533)\end{array}$ \\
\hline
\end{tabular}


De esta manera, el tercer sector se constituye como una de las principales fuentes institucionales del sentido del uso del término solidaridad en la publicidad.

Y el sector privado con fines de lucro se constituye como el colaborador más cercano, ya que sumando su emisión directa y en alianza con el tercer sector, participan en algo más de un tercio de las piezas emitidas. En cambio el sector público, sumando toda su participación, no alcanza a representar un $20 \%$.

La alta presencia del tercer sector se concreta mediante alianzas estratégicas con el sector privado con ánimos de lucro, posibilitadas por un mercado que les permite concurrir con intereses complementarios. Por ejemplo, mediante una ley de donaciones, las empresas publicitarias pueden ofrecer sus servicios a organizaciones de interés público sin fines de lucro aprovechando así una franquicia tributaria. Adicionalmente, para muchas empresas la figuración de su imagen vinculadas a este tipo de "causas sociales” forma parte de su plan de marketing social. Las alianzas permiten relaciones y ganancias bastante específicas para cada una de las partes. A continuación presentamos como ejemplo, la campaña "Un click un árbol" realizada entre LG (marca de productos electrónicos) y Un techo para Chile (fundación dedicada a la construcción de viviendas sociales), un ejemplar de esta campaña se presenta en la Figura 1.

Figura 1

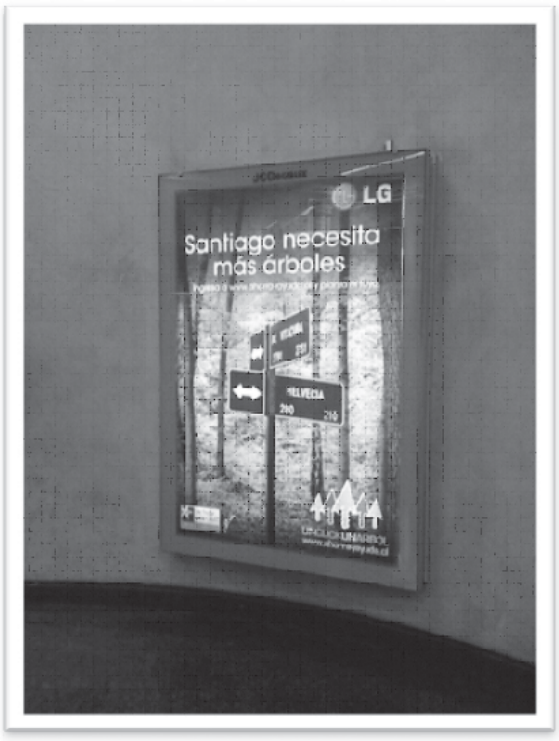

Fotografía tomada en una estación de Metro en Santiago 
La campaña funciona de la siguiente manera: la empresa LG donó 1 árbol por cada persona que se inscribió en el sitio web www.ahorrayayuda.cl ¿Qué ganan las instituciones por participar de esta campaña? LG, a través de la donación de 2000 árboles, se posiciona como una “marca verde”, preocupada por el medio ambiente, transfiriendo esta característica a sus productos (artefactos que ahorran energía), se construye como una empresa socialmente responsable, en tanto que trabaja con una de las fundaciones más importantes en nuestro país y además, logra instalarse como una "marca joven” pues Un techo para Chile es una fundación promovida como joven (tanto por quienes trabajan ahí, como por el tipo de voluntario que buscan). Un techo para Chile, por su parte, además de lograr una alianza estratégica con una empresa de gran presencia en el mercado, recibe árboles para cinco proyectos de viviendas definitivas. Así, la solidaridad es un negocio conveniente para ambos.

De esta forma la propiedad acerca del sentido de la solidaridad y las formas de practicarlas se estructuran a partir de una especie de mercado social, en donde el tercer sector y el sector privado con ánimos de lucro adquieren la mayor relevancia y poder sobre el discurso sobre solidaridad en la publicidad.

Esto es reflejo de la tendencia documentada a partir del 1973 en Chile, en que la propiedad sobre la solidaridad se traspasa crecientemente hacia la sociedad civil y el sector privado con ánimos de lucro.

\section{Prácticas solidarias: solidaridad de tránsito}

¿A qué se invita en las piezas publicitarias o qué prácticas solidarias se promueven? Fue lo que buscamos responder en el análisis de variedades de solidaridad. El resultado de este análisis se presenta en la Tabla 2.

\section{Tabla 2: Prácticas solidarias que son promovidas por las piezas publicitarias (en \% sobre el total de piezas)}

\begin{tabular}{|l|l|}
\hline Práctica solidaria promovida & $\%$ \\
\hline Solidaridad en el contexto de una compra & $\mathbf{2 3 , 8}$ \\
\hline Donaciones monetarias & $\mathbf{2 1 , 2}$ \\
\hline Solidaridad de gobierno/Protección de los vulnerados & $\mathbf{1 1 , 3}$ \\
\hline Ser socio & $\mathbf{1 0 , 1}$ \\
\hline RSE & $\mathbf{9 , 0}$ \\
\hline Voluntariado & $\mathbf{6 , 4}$ \\
\hline Reciclaje social y donación de otros objetos & $\mathbf{5 , 8}$ \\
\hline Intervención del tercer sector en problemáticas psicosociales & $\mathbf{3 , 8}$ \\
\hline Promoción de la solidaridad y otros valores asociados & $\mathbf{3 , 2}$ \\
\hline Donación de órganos & $\mathbf{2 , 8}$ \\
\hline Ayuda voluntaria simple & $\mathbf{1 , 9}$ \\
\hline Otros & $\mathbf{8}$ \\
\hline Total & $\mathbf{1 0 0 , 0}$ \\
\hline
\end{tabular}


Tal como se aprecia en la tabla, casi la mitad de las variedades de solidaridad que se promueven son de tipo dinerario, y se realizan en el contexto de una compra $(23,8 \%)$ o de una donación monetaria $(21,2 \%)$. Por solidaridad en el contexto de una compra se comprendieron las compras de productos solidarios (como una pulsera solidaria), productos solidarizados (por ejemplo, productos adheridos a la Teletón), la adquisición de servicios solidarizados (como servicios funerarios) y la donación del vuelto de una compra, entre otros. Mientras que la donación monetaria comprendió aquellas piezas que solicitan una donación monetaria puntual, fuera del contexto de una compra, que no se sostiene en el tiempo.

Ambas prácticas involucran poco dinero, son acciones fáciles que se acoplan a la actividad de consumo en o de trayectos cotidianos, rápidas y que no requieren un compromiso por parte de quien realiza la donación ${ }^{5}$. En la contraparte, la solidaridad impulsada por el Estado a través del gobierno reúne apenas un $11 \%$ y una solidaridad no monetarizada como el voluntariado sólo un $6,4 \%$.

Por ende, la solidaridad que se promueve mayoritariamente es afín a una gubernamentalidad liberal en tanto se resuelve en el mercado y convoca a una acción individual voluntarista. Se trata de una solidaridad que se materializa como donación pecuniaria voluntaria dentro del itinerario cotidiano trabajo-consumo.

En consistencia con el punto anterior, se trata de una solidaridad barata. Esto se vincula con la necesidad del mercado de la solidaridad de generar un consumidor solidario que esté siempre dispuesto a donar. Para el mercado de la solidaridad, no es conveniente quemar al consumidor solidario con una gran donación, sino más bien debe mantenerlo con la "necesidad" de donar. ¿Cómo se crea esta necesidad? Una de las estrategias que se puede apreciar, ha sido explicitar que "es barato ayudar”. Un ejemplo emblemático, corresponde a la campaña de Conail (Corporación de Ayuda al Niño Limitado) cuyo lema es "100 pesos no es nada” (ver Figura 2, página siguiente). La idea, aparentemente paradojal, es que justamente el consumidor sienta por un lado que ayudar no cuesta nada, es decir que son una suma cercana a nada ya ayudó, y al mismo tiempo, que ya que dona "nada", siga donando esas "nadas" (como esas monedas que sobran del vuelto de una compra). En este sentido, una solidaridad barata, no sólo aumenta sus probabilidades de reunir fondos, sino que contribuye a la producción y reproducción masiva de un consumidor solidario, que siente que en realidad no ha hecho mucho. 


\section{Figura 2}

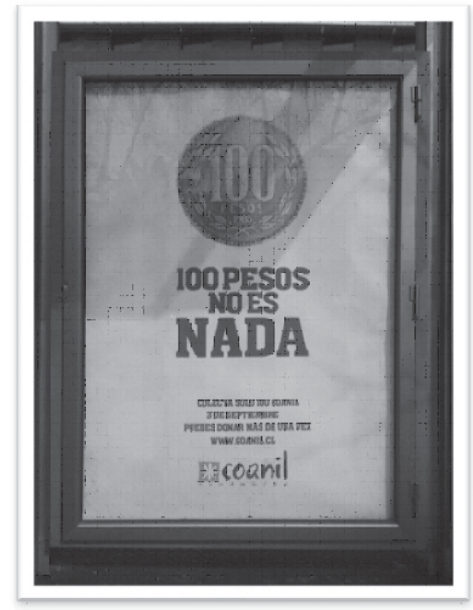

Fotografía tomada en una estación de buses en Santiago

\section{Sobre la interpelación solidaria}

En este punto quisimos enfatizar una mirada a la manera cómo se solicita la ayuda y a qué se apela para conseguir un acto solidario. Mediante un análisis multimodal distinguimos tres tipos de apelaciones según si interpelaban de manera racional, emocional o moral al sujeto enunciatario y codificamos la presencia o ausencia de este tipo de apelación para cada pieza.

- Apelación racional: se consignaron con presencia de apelación racional aquellas piezas que interpelan a la ayuda realizando algún tipo de argumento o explicación que habitualmente implicaba la entrega de información cuantitativa. Por ejemplo, se argumenta que ayudar de una manera determinada es eficiente o se presenta una ayuda como conveniente a través de una promoción o descuento ("Pague su patente aquí y aproveche de ayudar") o se argumenta que ayudar es fácil (“Ayude con un solo click”). Se trata de un interpelación que presupone algún tipo de cálculo racional antes de tomar la decisión de ayudar.

- Apelación emocional: se consideró que interpelaban emocionalmente aquellas piezas que apelan a sentimientos negativos (por ejemplo, mostrando la condición de sufrimiento de los potenciales beneficiarios) o positivos (por ejemplo, con frases como "ayudar es entretenido") utilizando una diversidad de recursos, tales como el uso de imágenes infantiles para enternecer, la utilización de conjugaciones verbales que construyen una relación de cercanía con el espectador (“juntos podemos”, "con tu ayuda”, "hoy 
queremos darte las gracias”, etc.) o presentar la ayuda en términos emotivos o emotivizados ("Un profesor puede cambiar la vida de un niño"), entre otros. Se trata de un interpelación que presupone la acción de ayuda como efecto de una reacción emocional de huida ante un sentimiento displacentero o de gozo empático por ayudar a otro.

- Apelación moral: se consignaron con presencia de apelación moral aquellas piezas con una sentencia o convocatoria moral explícita o implícita, a través de sentencias que suponen ciertos valores (ayudar a quienes lo necesitan es bueno), slogans de campañas ("Chile se levanta" o "Patente solidaria") o incluso a veces en los nombres o lemas de instituciones ("Un techo para Chile” o "María ayuda a la niña que sufre hoy”). En esta interpelación se vincula moralmente al sujeto enunciatario, de tal forma que se supone que la acción de ayuda del sujeto está movida por valores compartidos (que en este acto se construyen como tales en la misma enunciación) y que la realización de la acción de ayuda constituye también una acción moral sobre el sí mismo.

Los resultados de este análisis se presentan en la Tabla 3.

Tabla 3: Formas de apelación presentes en las piezas publicitarias (en \%)

\begin{tabular}{|l|l|}
\hline \multicolumn{1}{|c|}{ Tipo de apelación empleada ( $\left.^{*}\right)$} & $\mathbf{\%}$ \\
\hline Apelación racional & 34,1 \\
\hline Apelación emocional & 90,8 \\
\hline Apelación moral & 85,8 \\
\hline Total de piezas publicitarias & 533 \\
\hline
\end{tabular}

(*) Nota: En una pieza puede estar presente más de una apelación

Como resultado del análisis es interesante notar que más de dos tercios de las piezas $(68,9 \%)$ analizadas no presentan uso de una apelación racional. Por tanto, si bien se promueve una solidaridad altamente conveniente (tanto para las fundaciones y empresas que la impulsan, como para quien la realiza), dicha conveniencia no es una característica que se use para interpelar o solicitar la ayuda. Desde una perspectiva gubernamental, pareciera establecerse una especie de norma de cortesía respecto de la invocación a la acción de ayuda: "Se debe crear e instalar una solidaridad que sea un buen negocio, no obstante, esto no debe mencionarse ${ }^{6}$ ".

Ocurre lo contrario con la apelación emocional y moral. Casi todas las piezas $(90,8 \%)$ apelan a algún tipo de sentimiento para solici- 
tar la ayuda, así la solidaridad se ubica en el campo de lo emotivo y de lo sentimental, incluso lo psicológico (por ejemplo, el slogan de una campaña fue “Ayudar hace bien”). La mayoría de las piezas apelan a sentimientos positivos, motivando a los consumidores a ayudar por un gozo empático. En cuanto a la apelación moral, casi la totalidad de las piezas $(85,8 \%)$ usa una sentencia o una convocatoria moral implícita o explícita. En particular nos interesa como en ellas se sanciona quién merece ser ayudado y se construyen grandes causas morales.

A diferencia de una gubernamentalidad liberal social, en una gubernamentalidad liberal avanzada la solidaridad no es un derecho (Vázquez, 2005), sino que es una acción altruista dirigida a aquel grupo que no puede resolver por sí mismo su existencia. Para motivar la acción altruista de ayuda, es necesario que al potencial beneficiario no le sea imputada una responsabilidad sobre su condición de menesterosidad. La publicidad sobre solidaridad se ajusta a este doble canon. Además de la construcción de menesterosidad del destinatario, buena parte de las sentencias morales empleadas llegan a afirmar explícitamente la inocencia del potencial beneficiario: por ejemplo, en el spot de televisión de un hogar de menores, donde una niña luego de relatar una serie de sucesos de la crisis económica del 2009 dice: "Yo no provoqué nada de lo que está pasando, entonces ¿̇por qué me abandonas”.

Esto es consistente con la elección de beneficiarios y causas: casi la mitad de las piezas (46,5\%) solicita ayuda para niños (quienes por definición no son responsables de su condición de desgracia) y la causa para las que más se solicita ayuda están vinculadas a salud y desarrollo integral ${ }^{7}$ (22,9\%). Así, en la publicidad se asienta la máxima de que puede ser beneficiario de la ayuda quien se encuentra en una situación de necesidad radical tal, que no puede resolverla por sus propios medios y que además, no es responsable de su condición de necesidad, es decir, un inocente. En la contraparte, quien no cumpla con ambas condiciones queda excluido de la posibilidad de ser destinatario de solidaridad.

Adicionalmente apreciamos en la publicidad el uso del emblema que construye una "gran causa" para motivar la acción de colaboración en una campaña particular. Como ejemplo, se presenta una de las piezas de la campaña "2010 sin campamentos" de la fundación "Un techo para Chile" (ver Figura 3). 


\section{Figura 3}

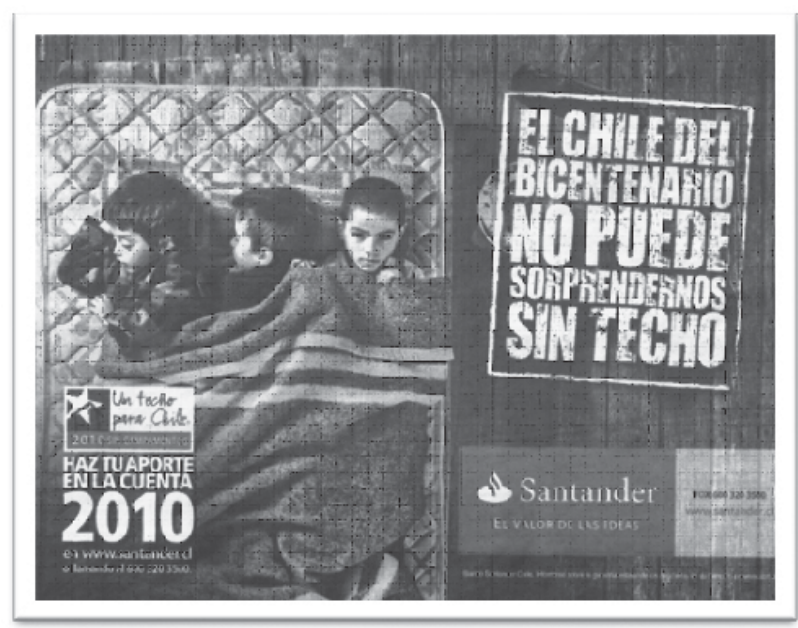

Pieza publicada en el diario La Tercera en junio de 2009

La pieza es lanzada en alianza estratégica entre Un techo para Chile y Banco Santander. Como la mayoría de las piezas, esta interpela emocionalmente: se muestran tres niños (sujetos inocentes) en condición de pobreza y hacinamiento, donde uno de ellos interpela con la mirada al espectador. En cuanto a los recursos lingüísticos la pieza utiliza tres vías para la construcción de su "gran causa”: i) el nombre emblemático y nacionalista de la fundación "Un techo para Chile", ii) una meta ambiciosa y magna como emblema de campaña "2010 sin campamentos" y iii) la sentencia moralmente imperativa "El Chile del Bicentenario no puede sorprendernos sin techo". Contrasta con la magnitud e importancia de esta gran causa la simplicidad de la ayuda solicitada: "Haz tu aporte en la cuenta 2010 en www.santander.cl o llamando al 600320 3500”. Así, realizar una donación con una simple llamada telefónica o vía Web es significada como ayudar a construir un país sin campamentos. De tal forma, suele darse en la publicidad sobre solidaridad esta relación entre solicitar una ayuda fácil y de bajo costo que, sin embargo, permite al donante vincularse a una gran causa solidaria.

\section{Conclusiones}

Cuando Foucault (2007) caracterizó la gubernamentalidad neoliberal norteamericana enfatizó en el modo en que se aplicaba una grilla económica a un campo que generalmente no compete a la economía como son los fenómenos sociales. Los resultados presentados parecen indicarnos que nos encontramos ante un asunto similar: la solidaridad traducida a una inteligibilidad neoliberal. 
Primero, tenemos la promoción mayoritaria de un tipo de solidaridad que tiene como condición para su realización ofrecerse como un mercado específico de la ayuda en el que puedan concurrir los intereses complementarios del tercer sector, la empresa privada con ánimos de lucro y el sector público.

Segundo, la generación de una oferta de alternativas de ayuda, principalmente de donaciones pecuniarias, voluntarias, puntuales y fáciles de realizar, y la simultánea construcción mediante la interpelación publicitaria de un sujeto como consumidor altruista.

Tercero, la fabricación de un mundo de la solidaridad patrocinado por fundaciones y empresas privadas protagonistas de "grandes causas" dirigidas a distintos tipos de personas que son víctimas de diferentes situaciones de necesidad y que convocan a la donación monetaria voluntaria interpelando al potencial colaborador a través de apelaciones en donde emotivismo y moral se confunden.

Ahora bien, al integrarse a un sistema de consumo, la solidaridad sufre los mismos efectos que cualquier objeto sometido a tal sistema: se vuelve un simulacro de sí misma (Baudrillard, 2009). Ibáñez (2002) describe este proceso de la mercantilización en el capitalismo de consumo como una exacerbación de la dimensión simbólica de los productos en desmedro de su dimensión material, e ilustra ese proceso relatando la historia de un refresco inicialmente hecho a base de naranjas exprimidas, que en luego de un proceso de mercantilización, finalmente sólo conservaba el nombre y el color de las naranjas. Al final del proceso sólo se conservan significantes, que luego sólo remiten a otros significantes, y así infinitamente.

La solidaridad parece haber pasado por un proceso similar: la publicidad invita a aportar a grandes causas (como es acabar con los campamentos) con acciones simples, fáciles y convenientes (como es donar un vuelto o realizando una llamada telefónica) que resultan cargadas de una semántica de altruismo y moralidad. Pero el sujeto no ha salido nunca de su circuito de trabajo- consumo, en donde de pronto, dejar el vuelto de una compra se transforma en una acción humanitaria (cien pesos pueden ser el desayuno de un niño huérfano, un techo para una familia o un pañal para un anciano solo) que lo hace partícipe de una gran causa de solidaria (acabar con el hambre, los sin techo o socorrer a la ancianidad desvalida).

La solidaridad es despojada de su antigua "materialidad" de contacto personal con el otro, de sacrificio o de "ideales políticamente pesados" como la justicia social, para conservar sólo una idea neutra de solidaridad como ayuda, que es completada con acciones enmarcadas en el libre mercado y proyectada simbólicamente en un mundo de la solidaridad mediante la publicidad.

En este contexto, la permanencia de la apelación a valores que tradicionalmente han inspirado la solidaridad (políticos, humanistas, cristianos, 
por nombrar algunos), es necesaria para un sistema donde la solidaridad se vuelve un producto de consumo: para la generación de un mundo simbólico para la realización del simulacro de la solidaridad. No interesa ya la manera en que una acción realizada se transforme en una ayuda material concreta hacia otro encarnado en situación de necesidad, como que una moneda se transfigure en un vaso de leche para un niño anónimo sonriente en un afiche en un farmacia, y me transfigure a mí como un sujeto altruista partícipe del humanitario mundo de la solidaridad.

En este sentido, este nuevo ethos de esta solidaridad de mercado promovida mayoritariamente en la publicidad es tremendamente afín a una gubernamentalidad liberal avanzada. Primero, porque consigue asimilar un ámbito que le era aparentemente opuesto como el de la solidaridad, ligado a nociones ajenas al mercantilismo y al liberalismo hedonista, como la gratuidad o el sacrificio, ganando en ella un nuevo nicho de mercado. Segundo, porque genera ese mercado mediante la creación de un ethos de la solidaridad de una moral emotivista y espontaneista que consigue conducir y capitalizar la moralidad de sus sujetos respetando su libertad individual. Y finalmente, porque en la publicidad reconstruye un mundo simbólico para la solidaridad que se nos ofrece hospitalariamente como hogar de la humanidad y al cuál se vuelve deseable pertenecer como miembro activo. 
Polis, Revista de la Universidad Bolivariana, Volumen 11, Nº 32, 2012

\section{Notas}

${ }^{1}$ Este artículo se enmarca dentro del proyecto FONDECYT 1090534.

${ }^{2}$ En este sentido, siguiendo a Agamben (1998) la solidaridad se levantaría como valor políco respecto de la vida, el único valor (por tanto, también el único desvalor) de las sociedades democráticas modernas.

${ }^{3}$ A diferencia de morales más antiguas, veáse por ejemplo las morales que Foucault (2002) desarrolla en La hermenéutica del sujeto.

${ }^{4}$ La recolección se realizó entre marzo del 2009 a enero del 2010, en el marco del proyecto FONDECYT 1090534

${ }^{5}$ Dentro de donación monetaria se incluyeron aquellas piezas en que se solicita una donación monetaria puntual que no se sostiene en el tiempo, si la donación es permanente se consignó como "Ser socio".

${ }^{6}$ Así como en la lógica del don la entrega de un regalo debe ir acompañada de gratuidad, pese a encontrarse sometida a una serie de reglas de recepción y entrega, en este caso la solidaridad debe aparecer como desinteresada aun cuando es movida por intereses (Komter, 2005).

${ }^{7}$ Cabe destacar que en la mayoría de los casos se trata de problemas de salud hereditarios que no pueden ser evitados. 


\section{Bibliografía}

Agamben, G. (1998), Homo sacer. El poder soberano y la nuda vida, Pretexto, Valencia.

Baudrillard, J. (2009), La sociedad de consumo, Siglo XXI, Madrid.

Bauman, Z. (2007), Vida de consumo, Fondo de Cultura Económica, Buenos Aires.

Cancino, B. (1996), “Las organizaciones no gubernamentales en Chile”. En B. Cancino, \& D. Vergara, La Asociación de los privados. ONG y organismos privados de desarrollo (págs. 6-22). Ediciones Sur, Santiago de Chile.

Cortina, A. (2002), Por una ética del consumo, Taurus, Montevideo.

De la Maza, G. (2003), “Sociedad civil y democracia en Chile”. En A. Panfichi, Sociedad civil, esfera pública y democracia en América Latina, Fondo de Cultura Económica, México, DF.

Dean, M. (2010), Governamentality: power and rule in modern society, Sage Publications, London.

Dockendorff, C. (1993), Solidaridad: la construcción social de un anhelo, MIDEPLAN/UNCEF/FOSIS, Santiago de Chile.

Dockendorff, C., Román, J. A., \& Energici, M. A. (2010), “La neoliberalización de la solidaridad”. Latin America Research Review, 45(1), 189-202.

Foucault, M. (2007), Nacimiento de la biopolítica. Curso en el College de France: 1978-1979, Fondo de Cultura Económica, Buenos Aires.

Hardy, C. (1986), Hambre + dignidad = ollas comunes, Programa de Economía del Trabajo (PET), Santiago de Chile.

Ibáñez, J. (2002), Por una sociología de la vida cotidiana, Siglo XXI de España Editores, Madrid.

Kress, G., \& van Leeuwen, T. (1996), Reading images, Routledge, Oxon.

Ídem (2001), Multimodal discourse, Arnold, Londres.

Román, J. A., \& Energici, M. A. (2006), “Solidaridad: el decurso de una invocación”. En D. Michelini, J. Wester, G. Müller, E. Romero, \& M. Bonyuan, Responsabilidad Solidaridad (págs. 74 - 81), Ediciones ICALA, Río Cuarto. 
Ídem (2010), “Solidaridad de mercado y los sujetos del capitalismo de consumo”. Psicología y Sociedade, 22(2).

Román, J. A., \& Ibarra, S. (2008), Solidaridad: significados, valores y prácticas, Facultad de Psicología, Universidad Alberto Hurtado, Santiago de Chile.

Román, J. A., Tomicic, A., \& Avendaño, C. (2007), “Solidaridad como problema”. Revista MAD, II(45), 151 - 183.

Rose, N. (2001), The Politics of Life Itself. Theory, Culture \& Society, 8(6), 1-30.

Ídem (2007), ¿La muerte de lo social? Re-configuración del territorio de gobierno. Revista Argentina de Sociología, 5(8), 111-150.

van Leeuwen, T. (2005), Introducing Social Semiotics, Routledge, Oxon.

Vázquez, F. (2005), “ ‘Empresarios de nosotros mismos’ Biopolítica, mercado y soberanía en la gubernamentalidad neoliberal” . En J. Ugarte, La administración de la vida. Estudios biopolíticos (págs. 73-103) Anthropos, Barcelona. 